\title{
Renal artery stenosis due to neurofibromatosis type 1: case report and literature review
}

\author{
Lian Duan ${ }^{1}$, Kai Feng ${ }^{1 *}$, Anli Tong ${ }^{1}$ and Zhiyong Liang ${ }^{2}$
}

\begin{abstract}
Background: Neurofibromatosis type 1 (NF1) is a relatively common autosomal dominant disorder. The most common vascular abnormality in patients with NF1 is bilateral or unilateral renal artery stenosis.

Case report: A 16-year-old boy presented with a headache of 4-year duration and was found to be moderately hypertensive. On physical examination, axillary freckling and multiple café-au-lait spots were revealed over the trunk, while numerous small nodules were palpable on the limbs. Biopsy of subcutaneous nodule showed neurofibroma. Lisch nodules were identified on slit-lamp examination and grade I hypertensive retinopathy was present on fundoscopy. Clinical laboratory investigations revealed that renal and liver function tests, blood cells count, urinalysis, serum electrolytes, serum levels of renin and aldosterone, and 24-hour urine levels of catecholamines were all within normal ranges. Abdominal ultrasound and $\mathrm{CT}$ were normal. Both kidneys were of normal size. $\mathrm{CT}$ angiography showed right renal artery stenosis (>90\%) at the ostium. The final diagnosis of NF1 with right renal artery stenosis and secondary hypertension was then made. The patient was treated with Procardin $(30 \mathrm{mg} / \mathrm{d})$ and improved with a significant decline in blood pressure. The main outcomes were to control blood pressure without necessarily proceeding with PTRA. We also present a review of the literature.

Conclusions: NF1 may present with hypertension due to renal artery stenosis in children. All young patients (<30 year) with hypertension should be clinically screened for secondary causes of hypertension, including NF1, so that renal revascularization can be offered before permanent end organ damage has occurred. First-line management using medication alone could be appropriate, keeping the interventional options for when the patient's condition deteriorates.
\end{abstract}

Keywords: Neurofibromatosis type 1, hypertension, renal artery stenosis

\section{Background}

Neurofibromatosis type 1 (NF1), formerly known as von Recklinghausen's disease, is an autosomal dominant disorder with a birth incidence of 1 in 2,500 to 3,000, independently of ethnicity and gender [1]. The gene responsible for NF1 is located on chromosome 17q11.2, and its protein product, neurofibromin, is ubiquitously expressed at high levels in the nervous system, and functions as a tumor suppressor.

Diagnosis is usually made on the basis of: 1) café-au-lait macules; 2) neurofibromas; 3) Lisch nodules of the iris; 4) axillary freckling; 5) optic pathway gliomas; 6) distinctive

\footnotetext{
* Correspondence: fengkai@medmail.com.cn

'Key Laboratory of Endocrinology, Ministry of Health; Department of Endocrinology, Peking Union Medical College Hospital, Peking Union Medical College and Chinese Academy of Medical Sciences, Beijing 100730, China Full list of author information is available at the end of the article
}

bone lesions; and 7) a first-degree relative with NF1 [2]. Other clinical manifestations are abnormalities of the cardiovascular, gastrointestinal, renal and endocrine systems, cognitive deficit, and malignancies of the peripheral nerve sheath and central nervous system [2].

The cardiovascular features of NF1 may include congenital heart disease, vasculopathy and hypertension. Vasculopathies are the second cause of death in NF1 patients [3]. The incidence of hypertension ( $>95$ th percentile for age and gender) in patients with NF1 is approximately $16 \%$ [4], and is mostly due to renal artery stenosis in children [5,6], followed by coarctation of the aorta and pheochromocytomas $[2,7,8]$. An annual blood pressure screening and heart examination are therefore warranted [2]. Any abnormal finding should be investigated with renal arteriography and 24-h urinary excretion of catecholamines and metabolites [9]. Magnetic

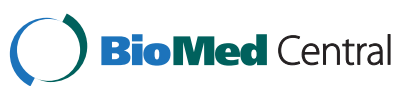

(c) 2014 Duan et al.; licensee BioMed Central Ltd. This is an Open Access article distributed under the terms of the Creative Commons Attribution License (http://creativecommons.org/licenses/by/2.0), which permits unrestricted use, distribution, and reproduction in any medium, provided the original work is properly credited. 
resonance imaging and computed tomography (CT) should be performed only after biochemical findings are observed [2,9].

The current management of NF1 focuses on symptomatic treatment. Therefore, early diagnosis of renal artery stenosis is important, because curative treatment can prevent the adverse consequences of hypertension. The blood pressure target in NF1 patients should be $<140 / 90 \mathrm{mmHg}[9,10]$. Renal angioplasty may be necessary, but may be insufficient to resolve hypertension, and drugs may be necessary [11-13].

We present and discuss the case of a 16-year old boy diagnosed with NF1 and unilateral renal artery stenosis. We focused on the first-line medical management, and reviewed the literature.

\section{Case presentation}

A 16-year-old boy was admitted to the Peking Union Medical College Hospital in June 2011, and presented with an intermittent headache of 4-year duration and was found to be moderately hypertensive. It was his first lifetime visit to a doctor. On physical examination, axillary freckling and multiple café-au-lait spots $\geq 5 \mathrm{~mm}$ in size were revealed, spread over the skin of the trunk (Figure 1), while numerous small nodules $\leq 1 \mathrm{~cm}$ were palpable in the limbs. The pigmentation was present when he was born. He was always lean because of low appetite, and had always achieved poor academic performance. His height was $166 \mathrm{~cm}$ (10th to 25th percentile for same age and gender [14]), weight was $43 \mathrm{~kg}$ and body mass index (BMI) was $15.6 \mathrm{~kg} / \mathrm{m}^{2}$.

Interestingly, his first-degree family history revealed no case of hypertension, cardiovascular diseases or NF1. Biopsy of a subcutaneous nodule resulted in diagnosis of a neurofibroma, which was confirmed by $\mathrm{S} 100$ protein immunoreactivity of many tumor cells (Figure 2). Lisch nodules were identified on slit-lamp examination and grade I hypertensive retinopathy was present on fundoscopy. All peripheral pulses were palpable and blood pressure was recorded in all four limbs using a mercury sphygmomanometer (three times, and using the mean): right $\operatorname{arm}=150 / 100 \mathrm{mmHg}$, left arm $=150 / 95 \mathrm{mmHg}$, right leg $=175 / 120 \mathrm{mmHg}$ and left leg $=170 / 115 \mathrm{mmHg}$. According to the 2010 blood pressure reference standard in Chinese children and adolescents, the 95th and 99th percentile of SBP (Systolic Blood Pressure) for 16-year old boys are $130 \mathrm{mmHg}$ and $141 \mathrm{mmHg}$, and the 95th and 99th percentile of DBP (Diastolic Blood Pressure) are $85 \mathrm{mmHg}$ and $91 \mathrm{mmHg}$ [15].

Clinical laboratory investigations revealed that renal and liver function tests, blood cell counts, urinalysis, serum electrolytes, serum levels of renin and aldosterone, and 24-h urine levels of catecholamines were all within normal ranges. Peripheral blood renin level was $0.34 \mathrm{ng} / \mathrm{ml} / \mathrm{h}$ measured in the supine position, and $1.56 \mathrm{ng} / \mathrm{ml} / \mathrm{h}$ measured in the standing position.

Ultrasound examination of the abdomen was normal. Both kidneys were of normal size (the right kidney was $10.1 \times 4.0 \times 4.1 \mathrm{~cm}$ and the left kidney was $11.3 \times 3.9 \times$ $3.8 \mathrm{~cm}$; cortical thickness was $0.6 \mathrm{~cm}$ for the right kidney, and $0.5 \mathrm{~cm}$ for the left). Abdominal CT did not show any adrenal or abdominal mass. CT angiography showed right renal artery stenosis (>90\%) at the ostium, but also that there was collateral circulation from the subphrenic artery (Figure 3). Blood flow was $36.7 \mathrm{ml} /$ minute in the right renal, and $57.1 \mathrm{ml} / \mathrm{minute}$ in the left. The final diagnosis of NF1 with right renal artery stenosis and secondary hypertension was then made.

The patient was treated with oral nifedipine sustainedrelease preparation (30 $\mathrm{mg}$ once a day), and improved with a significant decline in blood pressure (120 to 140/ 80 to $90 \mathrm{mmHg}$ ) after one week. Because: 1) the patient was young; 2) the right renal size was approximately normal; 3) the mild decrease in right renal blood flow was attributable to the collateral circulation; 4) the normal renin levels; and 5) improvements in blood pressure using drugs, the patient and his parents refused percutaneous transluminal renal angioplasty (PTRA) at this
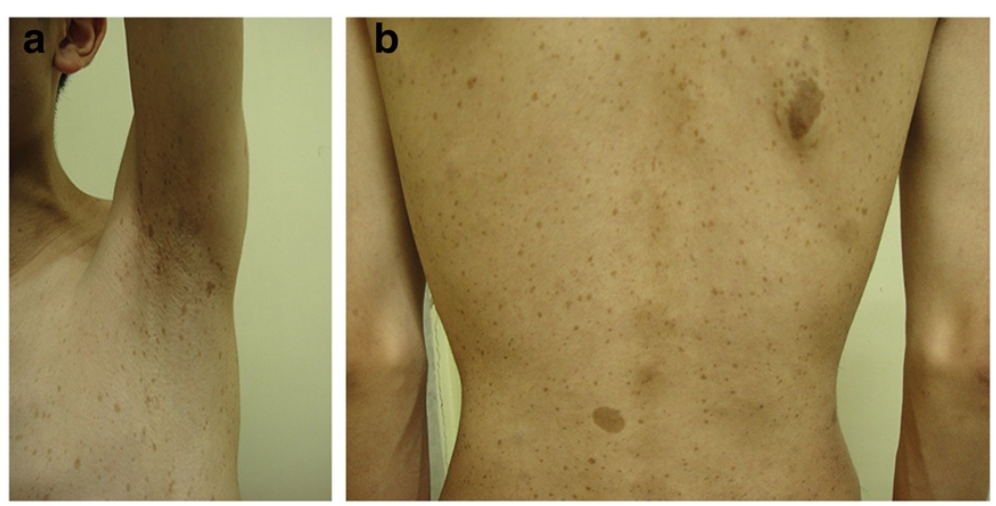

Figure 1 The special signs of the patient. Axillary freckling (a) and multiple caféau-lait spots (b) spread over the skin of the trunk. 

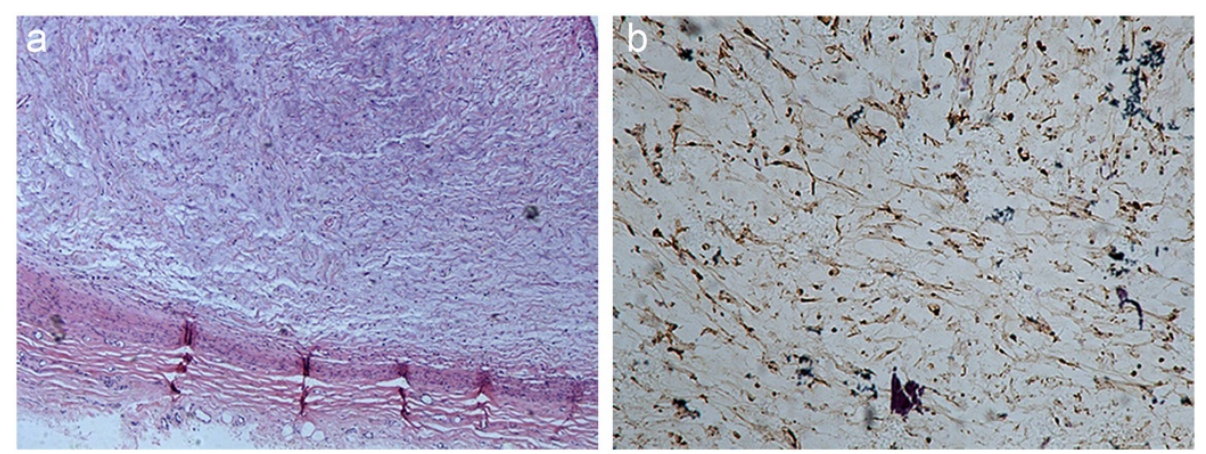

Figure 2 Pathology result of subcutaneous nodules. (a) Hematoxylin and eosin (HE) staining of subcutaneous nodules revealed the diagnosis of neurofibroma accompanied by mucinous degeneration (magnification $\times 40$ ). (b) Immunohistochemistry staining for S-100 protein was positive (magnification $\times 40$ ).

time. Therefore, the patient was discharged from our hospital after 1 month. The nifedipine treatment was continued and the patient was simply followed up with close monitoring of blood pressure, and renal function at least once every three months in our outpatient department. PTRA was kept as an option should the patient's condition deteriorate. Blood pressure was wellcontrolled during one year follow-up. The patient was lost to follow up after one year.

\section{Discussion}

We reported the case of a 16-year-old boy who presented with hypertension. He was diagnosed with NF1 and unilateral renal artery stenosis. Medical treatment alone improved his condition, and interventional treatment was kept as an option for an eventual deterioration of his condition. Therefore, medical treatment should be the initial approach to control hypertension in order to allow maximal body growth before any intervention. However, children with sustained hypertension despite optimal medical management should undergo intervention to avoid the progression of end-organ damage. Consequently, we monitored his blood pressure, renal function and renal blood flow.

Renovascular hypertension is an important cause of secondary hypertension in children, and is responsible for $3.0 \%$ to $8.5 \%$ of pediatric hypertension $[16,17]$. The most common causes of renovascular hypertension in children reported in the western literature are fibromuscular dysplasia (FMD) and midaortic syndrome [16]. However, Takayasu's arteritis is the most important cause of hypertension in Asian children [18]. Renal artery stenosis may also occur in association with NF1, Williams' syndrome, Marfan's syndrome, congenital Rubella syndrome, Kawasaki disease, and Crohn's disease [19].

NF1 typically presents with café-au-lait spots, multiple neurofibroma, axillary freckling, and ocular Lisch nodules [2]. About $16 \%$ of patients with NF1 develop hypertension [4], either essential hypertension or secondary hypertension due to renovascular disease, coarctation of

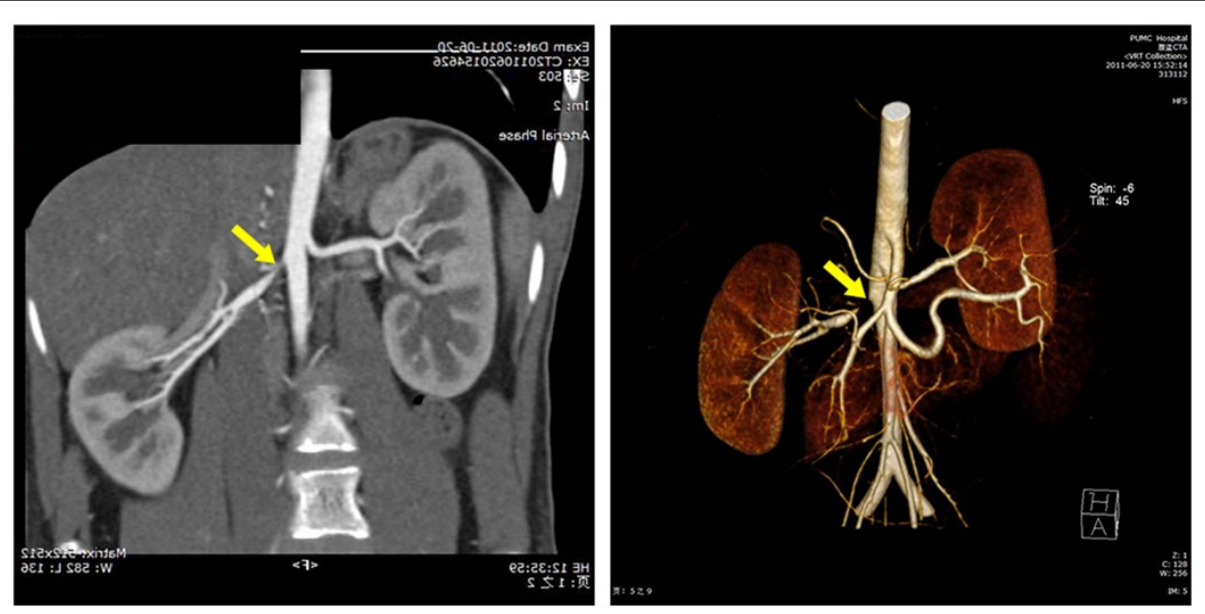

Figure 3 Computed tomography angiography of the renal vessels. The initial segment of the right artery was almost occluded, but there was a collateral circulation from the subphrenic artery. Blood flow was $36.7 \mathrm{ml} /$ minute in the right renal, and $57.1 \mathrm{ml} / \mathrm{minute}$ in the left. 
the abdominal aorta or pheochromocytoma [2,5-8]. In children and young adults with NF1, the most frequent cause of hypertension is renovascular disease, which occurs seven times more frequently than pheochromocytoma [9]. Renal artery stenosis in NF1 is usually ostial in location, as was seen in our case [9]. In contrast with fibromuscular dysplasia where $95 \%$ of all stenoses are found in the distal two-thirds of the renal artery, more than $50 \%$ of all stenoses in NF1 are located at the ostia [9].

Greene et al. originally described two basic categories of stenosis in NF1. The first involves larger vessels such as the aorta, carotid and proximal renal arteries, which are surrounded by neurofibromatosis or ganglioneuromatous tissue. Intimal proliferation, thinning of the media and fragmentation of elastic tissue may lead to stenosis or aneurysm formation. The second type is unrelated to neural malformation, but probably reflects dysplasia of small vessels. Lesions occur in many arteries and involve the minute intrarenal branches. Using electron microscopy, Greene et al. identified smooth-muscle elements within the abnormal cells and concluded that the vascular lesion is a form of mesodermal dysplasia [20]. The case presented here probably belongs to the first category.

Renovascular hypertension results in decreased blood flow to the kidney, resulting in increased production of renin. The aim of angioplasty is therefore to restore blood flow to the kidney, thereby decreasing renin production [21]. Treatment modalities in renovascular hypertension secondary to NF1 involve a combination of drug therapy, PTRA, and surgery [9-13]. Indeed, Kimura et al. reported good outcomes using renal artery repair in children, including NF1 patients $[12,13]$. Malav et al. [6] reported good outcomes using antihypertensive drugs and renal angioplasty, whereas Ueda et al. [11] and Booth et al. [22] reported persistent high blood pressure after renal angioplasty. Oderich et al. [3] reported safe, effective and durable outcomes of surgical management of NF1-associated hypertension. However, it is our opinion that medical treatment should be the initial approach for controlling hypertension to allow maximal body growth before any surgical intervention, which is also advocated by Tullus et al. [21]. However, we agree that poorly controlled hypertension using medical therapy is undesirable in children because of the progression of end-organ damage. A review of 16 NF1 patients with renal artery stenosis who underwent PTRA had a 33\% success rate with PTRA for primary stenosis. The success rate was higher (67\%) in post-surgery residual stenosis [22]. Because of the absence of major complications and no adverse effect on subsequent vascular reconstruction, PTRA should be considered as first-line treatment for renal artery stenosis in NF1 pediatric patients only when clinically indicated. In both NF1 and Takayasu's arteritis, the presence of ostial stenosis and long-segment disease predisposes to restenosis. Surgical treatment of renal artery stenosis by reimplanting the renal artery on the aorta, or bypassing the obstruction using the saphenous vein or splenic artery, have been reported with good results [17]. Although restenosis after PTRA is not uncommon, there are several advantages of PTRA over surgery. Reduced morbidity from the lack of a surgical incision and reduced hospital stay are desirable at all ages. Furthermore, PTRA does not interfere with subsequent surgery if it is needed. Stent angioplasty is technically successful and can improve hypertension in selected patients. However, arterial stenting is generally avoided in the pediatric population unless angioplasty results in a flow-limited dissection, complete recoil of stenosis, or focal arterial rupture [23].

Han and Criado [24] reviewed 13 papers including 49 patients with NF1 and renovascular hypertension, and who were treated with medication, surgery, or percutaneous transluminal angioplasty (PTA) or coil embolization. All patients received medical therapy. Eight patients were treated with medication alone, 10 had a nephrectomy, 13 had surgical revascularization procedures, 16 had a PTA, and 1 patient had transluminal embolization of an aneurysm. Medication alone improved the condition of $56 \%$ of the patients, but also led to failure in $22 \%$. However, this rate was similar to the failure rates of surgery (22\%) and PTRA (35\%).

In addition to renal artery stenosis, vascular lesions in NF1 may involve mesenteric vessels, aorta, and cerebral vessels. NF1 vasculopathy tends to be progressive and is one of the leading causes of death in this population [3]. Therefore, careful long-term follow up is therefore required.

\section{Conclusions}

NF1 may present with hypertension due to renal artery stenosis in children. A wider appreciation of this entity is warranted for early diagnosis and appropriate, prompt treatment. In summary, NF1 is a disorder usually associated with bilateral or unilateral renal artery stenosis. All young patients ( $<30$ years) with hypertension should be clinically screened very early for secondary causes of hypertension, including NF1, so that renal revascularization can be offered before permanent end-organ damage has occurred.

\section{Consent}

Written informed consent was obtained from the patient for publication of this Case report and any accompanying images. A copy of the written consent is available for review by the Editor-in-Chief of this journal. 


\section{Abbreviations}

CT: Computed tomography; FMD: Fibromuscular dysplasia; NF1: Neurofibromatosis type 1; PTRA: Percutaneous transluminal renal angioplasty.

\section{Competing interests}

The authors declare that they have no competing interests.

\section{Authors' contributions}

All authors participated in the preparation of the manuscript. LD collected all clinical data. All authors read and approved the final manuscript.

\section{Acknowledgements}

The authors acknowledge the contribution of Dr Xiaoping Xing for her insight. We thank Dr Xuan Wang for her technical assistance. There was no funding for the present study.

\section{Author details}

${ }^{1}$ Key Laboratory of Endocrinology, Ministry of Health; Department of Endocrinology, Peking Union Medical College Hospital, Peking Union Medical College and Chinese Academy of Medical Sciences, Beijing 100730, China. ${ }^{2}$ Department of Pathology, Peking Union Medical College Hospital, Peking Union Medical College and Chinese Academy of Medical Sciences, Beijing 100730, China

Received: 26 August 2013 Accepted: 12 March 2014

Published: 28 March 2014

\section{References}

1. Reynolds RM, Browning GG, Nawroz I, Campbell IW: Von Recklinghausen's neurofibromatosis: neurofibromatosis type 1. Lancet 2003, 361:1552-1554.

2. Williams VC, Lucas J, Babcock MA, Gutmann DH, Korf B, Maria BL: Neurofibromatosis type 1 revisited. Pediatrics 2009, 123:124-133.

3. Oderich GS, Sullivan TM, Bower TC, Gloviczki P, Miller DV, Babovic-Vuksanovic D, Macedo TA, Stanson A: Vascular abnormalities in patients with neurofibromatosis syndrome type I: clinical spectrum, management, and results. J Vasc Surg 2007, 46:475-484.

4. Tedesco MA, Di Salvo G, Ratti G, Natale F, Calabrese E, Grassia C, lacono A, Lama G: Arterial distensibility and ambulatory blood pressure monitoring in young patients with neurofibromatosis type 1. Am J Hypertens 2001, 14:559-566.

5. Srinivasan A, Krishnamurthy G, Fontalvo-Herazo L, Nijs E, Meyers K, Kaplan B, Cahill AM: Spectrum of renal findings in pediatric fibromuscular dysplasia and neurofibromatosis type 1. Pediatr Radiol 2011, 41:308-316.

6. Malav IC, Kothari SS: Renal artery stenosis due to neurofibromatosis. Ann Pediatr Cardioly 2009, 2:167-169.

7. Elias DL, Ricketts RR, Smith RB 3rd: Renovascular hypertension complicating neurofibromatosis. Am Surg 1985, 51:97-106.

8. Karagiannis A, Mikhailidis DP, Athyros VG, Harsoulis F: Pheochromocytoma: an update on genetics and management. Endoc Relat Cancer 2007, 14:935-956

9. Friedman JM, Arbiser J, Epstein JA, Gutmann DH, Huot SJ, Lin AE, McManus B, Korf BR: Cardiovascular disease in neurofibromatosis 1: report of the NF1 Cardiovascular Task Force. Genet Med 2002, 4:105-111.

10. Ferner RE, Huson SM, Thomas N, Moss C, Willshaw H, Evans DG, Upadhyaya M, Towers R, Gleeson M, Steiger C, Kirby A: Guidelines for the diagnosis and management of individuals with neurofibromatosis 1. J Med Genet 2007, 44:81-88.

11. Ueda K, Awazu M, Konishi Y, Takenouchi T, Shimozato S, Kosaki K, Takahashi T: Persistent hypertension despite successful dilation of a stenotic renal artery in a boy with neurofibromatosis type 1. Am J Med Genet Part A 2013, 161A:1154-1157.

12. Kimura H, Sato O, Deguchi JO, Miyata T: Surgical treatment and long-term outcome of renovascular hypertension in children and adolescents. Eur J Vasc Endovasc Surg 2010, 39:731-737.

13. Kimura H, Sato O, Deguchi JO, Miyata T: Surgical treatment of a patient with progressive thrombosis of the renal artery associated with neurofibromatosis. Int Angiol 2009, 28:503-506.

14. Li H, Ji CY, Zong XN, Zhang YQ: Height and weight standardized growth charts for Chinese children and adolescents aged 0 to 18 years [Article in Chinese]. Zhonghua er ke za zhi 2009, 47:487-492.
15. Liu LS: Writing Group of Chinese Guidelines for the Management of H: 2010 Chinese guidelines for the management of hypertension [Article in Chinese]. Zhonghua xin xue guan bing za zhi 2011, 39:579-615.

16. Hiner LB, Falkner B: Renovascular hypertension in children. Pediatr Clin North Am 1993, 40:123-140.

17. Stanley JC, Criado E, Upchurch GR Jr, Brophy PD, Cho KJ, Rectenwald JE, Michigan Pediatric Renovascular G, Kershaw DB, Williams DM, Berguer R, Henke PK, Wakefield TW: Pediatric renovascular hypertension: 132 primary and 30 secondary operations in 97 children. J Vasc Surg 2006, 44:1219-1228.

18. Arora P, Kher V, Singhal MK, Kumar P, Gulati S, Baijal SS, Jain S, Kumar A: Renal artery stenosis in aortoarteritis: spectrum of disease in children and adults. Kidney Blood Press Res 1997, 20:285-289.

19. Daniels SR, Loggie JM, McEnery PT, Towbin RB: Clinical spectrum of intrinsic renovascular hypertension in children. Pediatrics 1987, 80:698-704.

20. Greene JF Jr, Fitzwater JE, Burgess J: Arterial lesions associated with neurofibromatosis. Am J Clin Pathol 1974, 62:481-487.

21. Tullus K, Brennan E, Hamilton G, Lord R, McLaren CA, Marks SD, Roebuck DJ: Renovascular hypertension in children. Lancet 2008, 371:1453-1463.

22. Booth C, Preston R, Clark G, Reidy J: Management of renal vascular disease in neurofibromatosis type 1 and the role of percutaneous transluminal angioplasty. Neph Dial Transplant 2002, 17:1235-1240.

23. Konig K, Gellermann J, Querfeld U, Schneider MB: Treatment of severe renal artery stenosis by percutaneous transluminal renal angioplasty and stent implantation: review of the pediatric experience: apropos of two cases. Pediatr Nephrol 2006, 21:663-671.

24. Han M, Criado E: Renal artery stenosis and aneurysms associated with neurofibromatosis. J Vasc Surg 2005, 41:539-543.

doi:10.1186/2047-783X-19-17

Cite this article as: Duan et al:: Renal artery stenosis due to neurofibromatosis type 1: case report and literature review. European Journal of Medical Research 2014 19:17.

\section{Submit your next manuscript to BioMed Central and take full advantage of:}

- Convenient online submission

- Thorough peer review

- No space constraints or color figure charges

- Immediate publication on acceptance

- Inclusion in PubMed, CAS, Scopus and Google Scholar

- Research which is freely available for redistribution 